\title{
Thermochemical Aerobic Oxidation Catalysis in Water Proceeds via Coupled Electrochemical Half-Reactions
}

\author{
Jaeyune Ryu, Daniel T. Bregante, William C. Howland, Ryan P. Bisbey, Corey J. Kaminsky, Yogesh \\ Surendranath* \\ Department of Chemistry, Massachusetts Institute of Technology, Cambridge, Massachusetts 02139, United States
}

\begin{abstract}
Heterogeneous aqueous-phase aerobic oxidations are an important emerging class of catalytic transformations, particularly for upgrading next generation bio-derived substrates. The mechanism of these reactions and the precise role of $\mathrm{O}_{2}$ in particular remains unclear. Herein, we test the hypothesis that thermochemical aerobic oxidation proceeds via two coupled electrochemical half-reactions for oxygen reduction and substrate oxidation. We collect electrochemical and thermochemical data on common noble metal catalysts under identical reaction/transport environments, and find that the electrochemical polarization curves of the $\mathrm{O}_{2}$ reduction and the substrate oxidation half-reaction closely predict the mixed potential of the catalyst measured in operando during thermochemical catalysis across 13 diverse variables spanning reaction conditions, catalyst composition, reactant identity, and pH. Additionally, we find that driving the oxidation half-reaction reaction electrochemically in the absence of $\mathrm{O}_{2}$ at the mixed potential leads to very similar rates and selectivities as for the thermochemical reaction in all cases examined. These findings strongly indicate that the role of $\mathrm{O}_{2}$ in thermochemical aerobic oxidation is solely as an electron scavenger that provides an incipient electrochemical driving force for substrate oxidation. These studies provide a quantitative and predictive link between thermochemical and electrochemical catalysis, thereby enabling the rational design of new thermochemical liquid-phase aerobic oxidation schemes by applying the principles of electrochemistry.
\end{abstract}

Heterogeneous aerobic oxidations constitute a broad class of transformations critical for the valorization of small molecules, the remediation of waste streams, and the upgrading of biomass substrates. ${ }^{1,2,3}$ For complex and non-volatile substrates, in particular, heterogeneous aerobic oxidations must be conducted in the liquid phase and water can serve as an environmentally benign medium for these transformations. Accordingly, intensive research has been focused on developing aqueous-phase aerobic oxidation methodologies to reduce the environmental impact of chemical synthesis and manufacturing. Noble metals including Pt, $\mathrm{Pd}$, and $\mathrm{Au}$ have been identified as potent catalysts for the aqueous phase aerobic oxidation of small molecules..$^{3,4,5,6,7}$ In contrast to the rich mechanistic understanding of heterogeneous aerobic oxidation at gas-solid interfaces, there remains limited insight into the mechanism of aerobic oxidations mediated at a metal-aqueous interfaces, impeding the systematic development of improved catalysts for selective and efficient aerobic oxidation of next-generation bio-derived feedstocks.

Despite the extensive research efforts to unravel the mechanism of aqueous-phase aerobic oxidation of simple organic molecules like methanol, ethanol, and formic acid, the role of $\mathrm{O}_{2}$ in the mechanism remains the subject of vigorous debate. ${ }^{3,8,9,10}$ Researchers have invoked the direct participation of adsorbed $\mathrm{O}^{*}$ species in catalysis via Langmuir-Hinshelwood recombination with surfacebound organic intermediates. ${ }^{4,8,11,12}$ Alternatively, researchers have invoked an indirect role of $\mathrm{O}_{2}$ in scavenging electrons produced via substrate oxidation. The indirect role of $\mathrm{O}_{2}$ is supported by isotopic tracer studies, in which oxidations with ${ }^{18} \mathrm{O}_{2}$ show negligible incorporation of the ${ }^{18} \mathrm{O}$ label in the oxidation products. ${ }^{3}$ These labeling studies, in conjunction with computational modeling led to the postulate that the overall reaction might be comprised of two countervailing electrochemical half-reactions for the reduction of $\mathrm{O}_{2}$ to water and the oxidation of the small organic molecule to the product. ${ }^{9,13}$ This provocative hypothesis, if validated, would provide a clear connection between the largely disparate communities of thermochemical and electrochemical catalysis and have profound implications for the mechanistic understanding and rational design of liquid-phase thermochemical reactions and catalysts. ${ }^{14,15}$ Yet, direct insight into whether or not these reactions are electrochemical in nature remains elusive.

Historically, mixed potential theory (MPT) has been used to understand the coupling of electrochemical half-reactions at a solidliquid interface. MPT has been used to explain and analyze a rich array of surface reactions ranging from corrosion, to cathodic protection, and electroless plating. ${ }^{16,17,18,19,14}$ Although the basic foundation of MPT is well-established, it's use in the context of heterogeneous catalytic reactions has been largely restricted to simple cases in which the co-reactant is engaging in outer-sphere electron transfer. ${ }^{20,21,22}$ However, MPT can be equally effectively applied to a situation in which each half-reaction proceeds via a complex inner-sphere, surface catalyzed reaction mechanism. Despite its generality, MPT has, to the best or our knowledge, not yet been applied to analyze the aerobic oxidation of organic small molecules in a quantitative manner. 
a

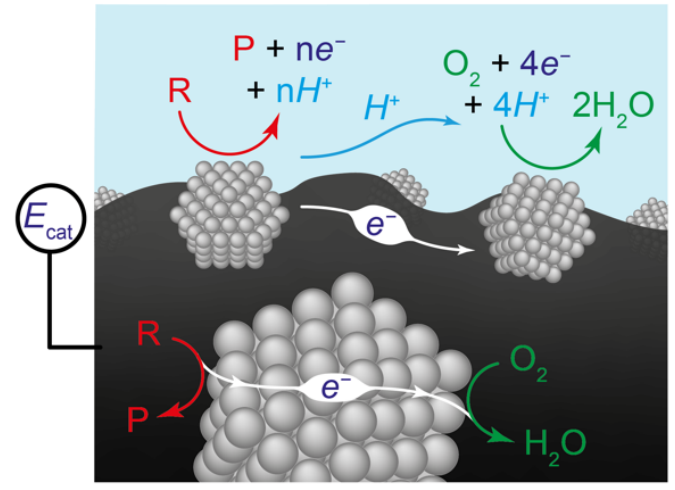

b

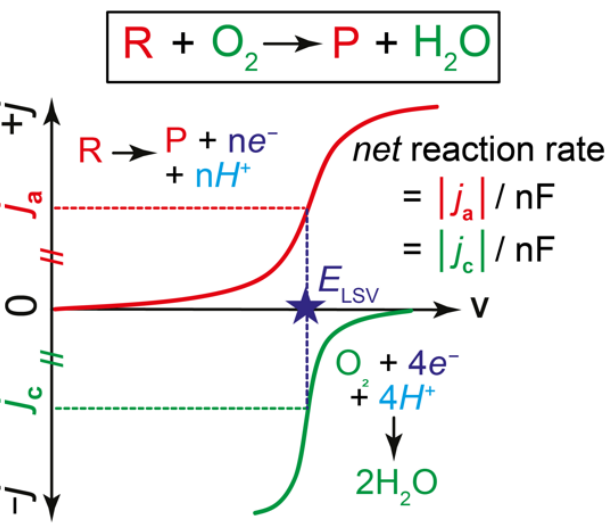

Fig. 1. (a) Thermochemical aerobic oxidation catalysis could proceed via coupled electrochemical half-reactions for substrate oxidation ( $\mathrm{R}$ to $\mathrm{P}$ ) and oxygen reduction. For simplicity, the scheme depicts full reduction of $\mathrm{O}_{2}$ to water. (b) Within the framework of mixed-potential theory, the independent electrical polarization curves for each half-reaction predict the mixed-potential and the reaction rate during thermochemical catalysis. $E_{\text {cat }}$ in (a) refers to the potential of the catalyst during thermochemical turnover while $E_{\mathrm{LSV}}$ in $(\mathbf{b})$ refers to the catalyst potential predicted by applying the current matching condition to the electrochemical polarization curves.

Within the framework of MPT, each catalyst particle functions as a short-circuited electrochemical cell where both electrochemical half reactions occur to generate an equal and opposite flux of current. Thus, under the influence of each half-reaction, this shortcircuit (SC) model predicts that the catalyst maintains a steady state mixed electrochemical potential that balances the flow of charge into and out of the particle (Fig. 1a). In the limit that the two electrochemical half-reactions are completely orthogonal from each other, the mixed potential expected during turnover can be predicted by simply overlaying the electrochemical polarization curves of the catalyst for each half-reaction measured in the absence of the co-reactant (Fig. 1b). Thus, a rigorous validation of the SC model requires (a) in operando measurement of the catalyst potential during thermochemical turnover and (b) evaluation of the polarization curves for the catalyst under identical reaction/transport conditions as for thermochemical catalysis. If the SC model is valid, (i) the current equivalency point of the polarization curves, $E_{\mathrm{LSV}}$ in Fig. 1b, should predict the mixed potential of the catalyst, $E_{\text {cat }}$ in Fig. 1a, during thermochemical turnover and (ii) electrochemically-driven catalysis at the mixed potential should give rise to the same reaction rate and selectivity as the thermochemical reaction. These diagnostic criteria, if satisfied, would provide solid support for an electrochemical mechanism underpinning thermochemical aqueous-phase aerobic oxidation catalysis.

Herein, we establish a general framework for analyzing a wide variety of aqueous-phase aerobic oxidation reactions within the context of MPT. By measuring electrochemical and thermochemical data under identical reaction/transport environments, we show that the electrochemical polarization curves of oxygen reduction reaction (ORR) and the substrate oxidation half reaction predict the potential of the catalyst measured in operando during thermochemical catalysis. We also show that driving the oxidation reaction electrochemically in the absence of $\mathrm{O}_{2}$ at the mixed potential leads to the same rate and selectivity as the thermochemical reaction. We use these observations to show that the short-circuit (SC) model accurately predicts catalyst potential, reaction rate, and general scaling behaviors in aerobic oxidation across reaction conditions, catalyst composition, reactant identity, and pH. These studies provide quantitative and predictive insight into the operation of thermochemical aerobic oxidation at metal-aqueous interfaces and highlight the commonality between electrochemical and thermochemical liquid-phase catalysis.

\section{RESULTS AND DISCUSSION}

\section{Quantifying short-circuit behavior within a model reaction: Pt-catalyzed formic acid oxidation}

In order to rigorously test the short-circuit hypothesis, we employed catalyst particles supported on a graphitic carbon conductive support and fashioned the catalyst/support network into a macroscopic electrode. This allowed for (I) the (mixed) potential of the catalyst to be monitored during thermochemical catalytic turnover, and (II) the electrochemical current-voltage behavior for each half-reaction to be measured independently. By employing a common catalyst network for the measurement of (I) and (II), this approach serves to test the SC model without any mechanistic assumptions or extrapolation of the electrochemical polarization data.

To test the validity of the SC model for aerobic oxidation, we begin with a model reaction: Pt-catalyzed aerobic oxidation of formic acid (FA) in acidic aqueous media ( $\mathrm{pH} 1)$. We employed nanoparticulate $\mathrm{Pt}$ on carbon (Pt/C) deposited as a thin film on a hydrophobic, electrically-conductive gas diffusion layer. This configuration facilitated efficient gas transport to the catalyst particles despite the low solubility of $\mathrm{O}_{2}$ in water (unless otherwise stated, this gas diffusion configuration was employed throughout this work; see Supporting Information for details). For this test reaction, gaseous reaction products were monitored by in-line gas chromatography and $\mathrm{CO}_{2}$ was found to be the sole product of FA oxidation in all cases.

The SC model predicts that the net thermochemical formic acid oxidation reaction, Eq. (1), proceeds via the coupling of two electrochemical half reactions, the formic acid oxidation reaction (FAOR), Eq. (2), and the oxygen reduction reaction (ORR), Eq. (3).

$$
\begin{aligned}
& \mathrm{HCOOH}+1 / 2 \mathrm{O}_{2} \rightarrow \mathrm{CO}_{2}+\mathrm{H}_{2} \mathrm{O} \\
& \mathrm{HCOOH} \rightarrow \mathrm{CO}_{2}+2 \mathrm{H}^{+}+2 \mathrm{e}^{-} \\
& 1 / 2 \mathrm{O}_{2}+2 \mathrm{H}^{+}+2 \mathrm{e}^{-} \rightarrow \mathrm{H}_{2} \mathrm{O}
\end{aligned}
$$


Thus, to test the SC model, we first recorded the electrochemical polarization behavior of (2) and (3) in the absence of the coreactant. As seen in Fig. 2a, the independently recorded polarization curves of FAOR in the absence of $\mathrm{O}_{2}(\mathrm{red})$ and $\mathrm{ORR}$ in the absence of FA (blue) reach inverse current values (i.e. equal in magnitude but opposite in sign) at $0.72 \mathrm{~V}$ vs the reversible hydrogen electrode (RHE). All potentials in this study were found to have a standard error of $\pm 0.01 \mathrm{~V}$ obtained from 3 or more independent replicates. This current-equivalency point provides a predicted SC potential $\left(E_{\mathrm{LSV}}\right)$ for the overall thermochemical reaction if the $\mathrm{SC}$ model were operative. Using the same catalyst on which the polarization data were recorded, we monitored the open-circuit potential $\left(E_{\text {cat }}\right)$ during net thermochemical aerobic oxidation catalysis (Eq. (1)). We stress that during thermochemical catalysis, no current is flowing through an external circuit, but the electrical connection to the catalyst provides for a real-time quantitative measurement of the catalyst potential. Upon initiating the thermochemical reaction, the measured $E_{\text {cat }}$ rapidly stabilized and remained fixed at $0.75 \mathrm{~V}$, which is very close to the value $\left(E_{\mathrm{LSV}}, 0.72 \mathrm{~V}\right)$ predicted by the independently measured polarization curves of the ORR and FAOR electrochemical half-reactions (Fig. 2b, top).

In addition to the steady-state potential of catalysis, comparison of the reaction rate under electrochemical and thermal catalytic conditions provides an addition handle with which to test the applicability of the SC model. Under thermochemical aerobic oxidation conditions, we measure a steady state specific rate of $3.1 \pm 0.3 \mathrm{mmol}_{\mathrm{CO}_{2}} \mathrm{hr}^{-1} \mathrm{mg}_{\mathrm{Pt}^{-1}}$ (Fig. 2b, bottom). We note that this and all other rate measurements were taken at less than $10 \%$ conversion to minimize substrate depletion effects. Strikingly, in the absence of absence of $\mathrm{O}_{2}$, electrochemically driven FAOR at $0.75 \mathrm{~V}$, leads to a steady-state specific reaction rate of $2.7 \pm 0.2 \mathrm{mmol}_{\mathrm{CO}_{2}} \mathrm{hr}^{-1}$ $\mathrm{mg}_{\mathrm{Pt}}{ }^{-1}$, very much in line with the value recorded under thermochemical aerobic oxidation conditions. The close similarity in both the predicted potential and the reaction rate suggest that aerobic FA oxidation catalysis is well described by the SC model.

We note that the Pt catalyst nanoparticles in this study were supported on carbon $(\mathrm{Pt} / \mathrm{C})$, which is a common support material in the aerobic oxidation literature. ${ }^{4,7}$ Notably, the same correspondence between catalyst potential and reaction rate is also observed on a Pt mesh catalyst (Fig. S1), suggesting that the carbon support does not play a specific role in the SC model other than serving as a conductive network with which to readily sample the catalyst potential. Furthermore, the $\sim 5 \mathrm{~nm} \mathrm{Pt}$ nanoparticles in $\mathrm{Pt} / \mathrm{C}$ are $\mathrm{known}$ to display metallic electronic structure; ${ }^{23,24}$ consequently, we expect that the behavior of bulk Pt is maintained on each individual Pt particle supported on carbon.

As a further test of the SC model, we tracked the temporal variation of the catalyst potential and reaction rate in real-time using on-line electrochemical mass spectrometry. We positioned the $\mathrm{Pt} / \mathrm{C}$ gas diffusion layer at the inlet to the mass spectrometer (MS) (see Fig. S2 and SI for full experimental details) and tracked the formation of $\mathrm{CO}_{2}$ as the $44 \mathrm{~m} / \mathrm{z} \mathrm{MS} \mathrm{signal} \mathrm{(Fig.} \mathrm{2c).} \mathrm{In} \mathrm{the} \mathrm{presence} \mathrm{of}$ FA under Ar flow (0 to $30 \mathrm{~s}$ ), we observe no appreciable $\mathrm{CO}_{2}$ by $\mathrm{MS}$ (Fig. 2c, top) and a stable $E_{\text {cat }}$ of $\sim 0.1 \mathrm{~V}$ (Fig. 2c, bottom). Upon rapid switching of the gas flow to $\mathrm{O}_{2}$ at the $30 \mathrm{~s}$ time point, we observe a synchronous rise of both the $\mathrm{CO}_{2}$ signal in the $\mathrm{MS}$ and the $E_{\text {cat }}$ (Fig. 2c, yellow highlighted regions), before reaching steady state values at $\sim 50 \mathrm{~s}$. The measured $E_{\text {cat }}$ at steady state is again $\sim 0.75 \mathrm{~V}$, close to the value $\left(E_{\mathrm{LSV}}\right)$ estimated by the independently measured polarization curves. The synchronous rise of $E_{\text {cat }}$ and the product formation rate under thermochemical conditions provides additional support for the coupled electrochemical nature of thermochemical FA oxidation.

Together, the above electrochemical, chemical, and spectrometric studies strongly support a model for aerobic thermochemical FA oxidation that proceeds via two largely independent electrochemical half-reactions, FAOR and ORR that are coupled together simply via electron flow through the catalyst. Thus, independent measurement of the electrochemical half reactions predicts the potential of
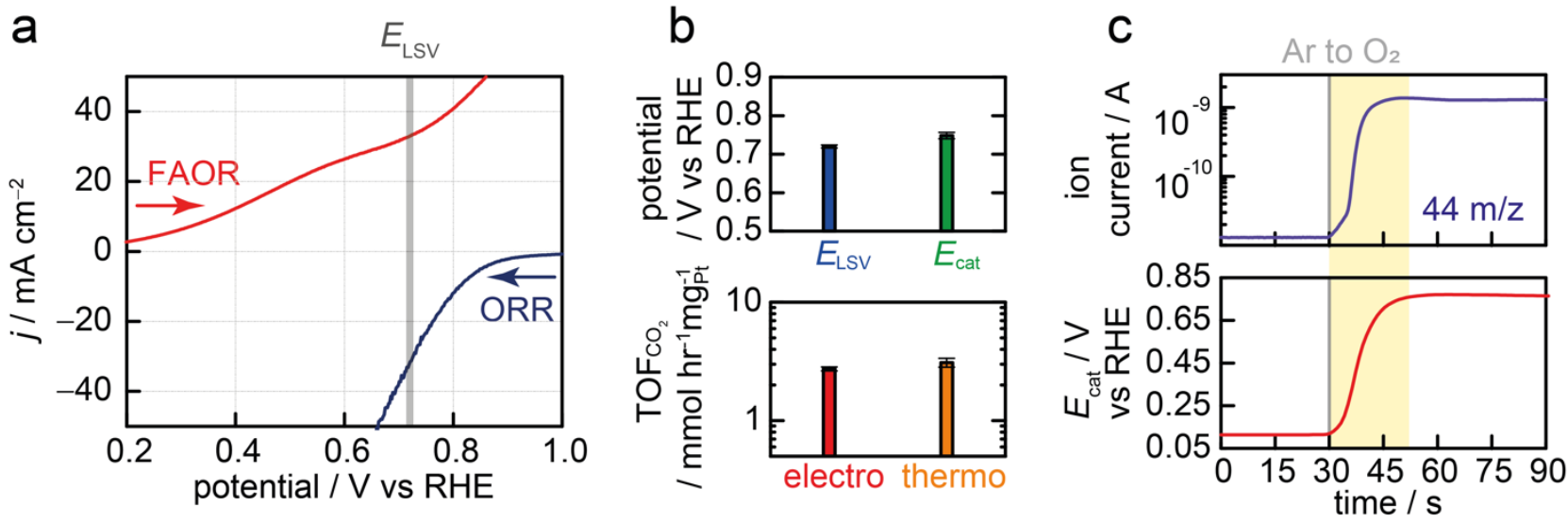

Fig. 2. (a) Linear sweep voltammograms (LSVs) of Pt/C catalyzed formic acid oxidation reaction (FAOR, red) and oxygen reduction (ORR, blue) at $\mathrm{pH} 1\left(0.1 \mathrm{M} \mathrm{HClO}_{4}\right)$, scan rate: $10 \mathrm{mV} \mathrm{s}^{-1}$. The arrows indicate the direction of scan. The FAOR curve was collected with $0.5 \mathrm{M}$ of formic acid (FA) in the absence of $\mathrm{O}_{2}$, whereas the ORR curve was collected without formic acid (FA) under $1 \mathrm{~atm}$ of $\mathrm{O}_{2}$. The current equivalency point $\left(E_{\mathrm{LSV}}\right)$ is marked (vertical grey bar). (b, top) Comparison of the expected catalyst potential, $E_{\mathrm{LSV}}$ (blue bar) and measured catalyst potential, $E_{\text {cat }}$ (green bar) during thermochemical FA oxidation. (b, bottom) Comparison of the measured specific reaction rates during electrochemically-driven FAOR at $E_{\text {cat }}$ (red bar) and thermochemical FA oxidation (orange bar). (c) Real-time monitoring of the temporal variation in mass spectrometer (MS) signal for $\mathrm{CO}_{2}\left(44 \mathrm{~m} / \mathrm{z}\right.$, top) and catalyst potential, $E_{\text {cat }}$ (bottom). Upon switching the sweep gas from $\mathrm{Ar}$ to $\mathrm{O}_{2}$ at $30 \mathrm{~s}$, both signals exhibit synchronous transients (yellow) prior to reaching steady-state values at $\sim 50 \mathrm{~s}$. The recorded electrochemical currents in (a) are normalized by the geometric surface areas of the electrodes contacted with the reaction solution. Error bars indicate standard errors, obtained from 3 or more independent replicates. 
the electron bath in the metal. Additionally, removing Fermi electrons (or equivalently injecting holes) via an external circuit or via inner-sphere $\mathrm{O}_{2}$ reduction catalysis provides the same reaction rate for FA oxidation. Indeed, under thermochemical conditions, $\mathrm{O}_{2}$ functions to raise and maintain the catalyst potential at a sufficient high value $(>0.7 \mathrm{~V})$ to drive electrochemical FAOR and the matched electron exchange between the two half reactions maintains the redox-neutrality of the net reaction.

The foregoing observations constrain the palette of viable mechanistic pathways since the surface intermediates involved in thermochemical FA oxidation must also be accessible via electrochemical polarization at $E_{\text {cat }}$. Indeed, since the $E_{\text {cat }}$ value of $\sim 0.7 \mathrm{~V}$ is at $\mathrm{a} \sim 0.5 \mathrm{~V}$ underpotential to the thermodynamic potential, $1.23 \mathrm{~V}$, for electrochemical $\mathrm{O}_{2}$ production, the above data explicitly excludes Langmuir-Hinshelwood mechanistic sequences involving adsorbed $\mathrm{O}_{2}{ }^{*}$, a pathway previously invoked for aerobic oxidation. ${ }^{4}$ Instead, extensive studies of Pt electrochemistry establish that at $0.7 \mathrm{~V}$, the Pt surface is expected to be partially covered with adsorbed $\mathrm{OH}^{*}$ implying that these adsorbates, which are in equilibrium with free proton and electrons, facilitate FA oxidation during both electrochemical and thermochemical catalysis. ${ }^{3}$ Indeed, these mechanistic conclusion from MPT theory are in line with the proposed reaction sequence of glycerol oxidation on $\mathrm{Au}$ in alkaline media in which $\mathrm{O}_{2}$ reduction is postulated to replenishes $\mathrm{OH}^{-}$while scavenging electrons to maintain electro-neutrality of the overall catalytic cycle. ${ }^{3}$ Irrespective of the specific mechanism and microkinetic model at play, the foregoing observations indicate the inherent commonality between electrochemical and thermochemical aerobic oxidation catalysis.

The short circuit model provides a detailed picture of how reaction variables influence aerobic oxidation catalysis

The foregoing studies provide a framework for analyzing and predicting how reaction rate and potential are expected to be influenced by key reaction variables. Here, we examine the utility of the SC model in analyzing the impact of mass transport limitations and changes in reactant concentration (Fig. 3).
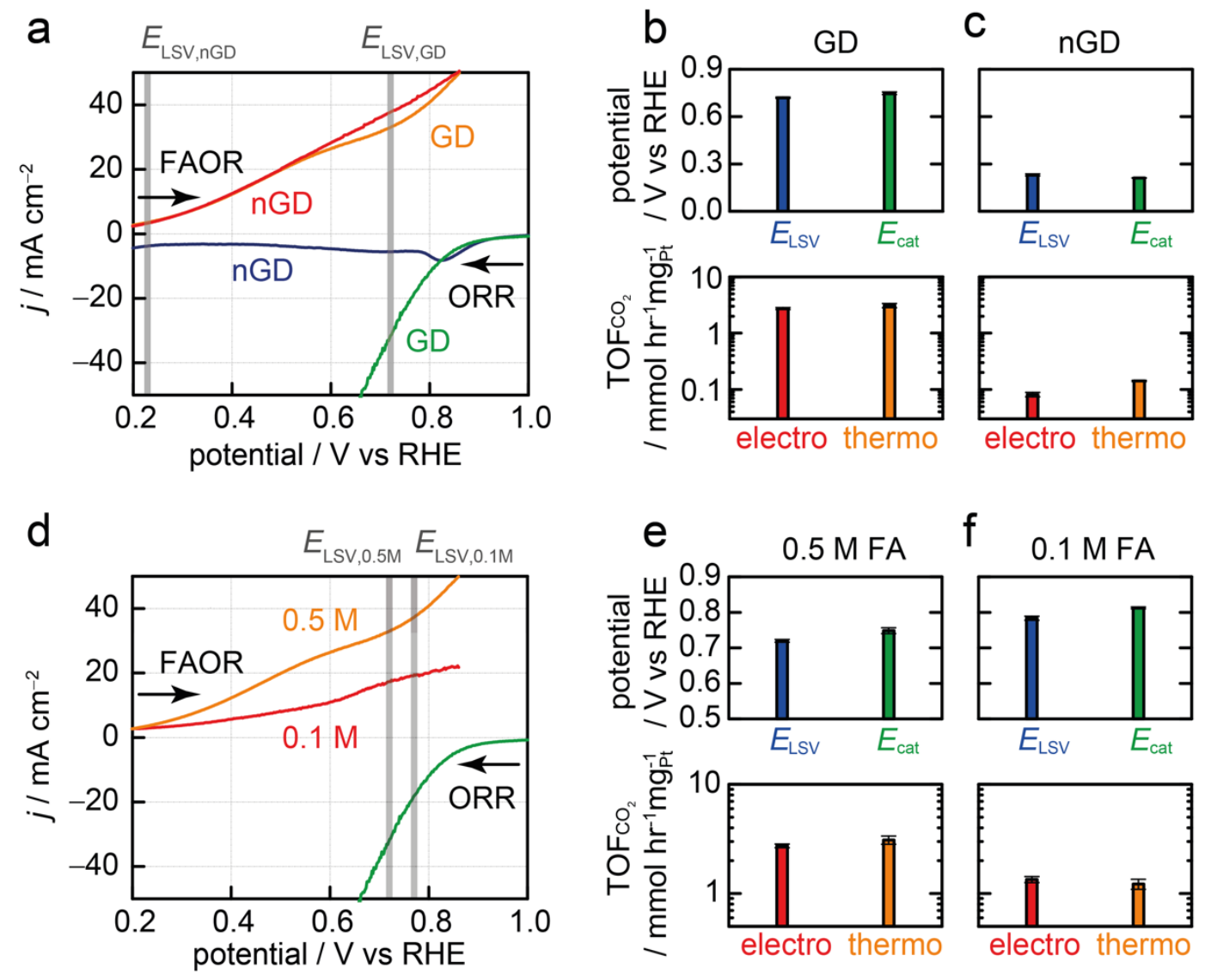

Fig. 3. (a) FAOR and ORR LSVs of Pt/C under disparate mass transport conditions of $\mathrm{O}_{2}$, scan rate: $10 \mathrm{mV} \mathrm{s}^{-1}$. Data were collected with $\mathrm{O}_{2}$ delivery through a gas-diffusing (GD) layer and via dissolved $\mathrm{O}_{2}$ without a gas-diffusion layer (nGD) at $\mathrm{pH} 1(0.1 \mathrm{M} \mathrm{HClO} 4)$. The current equivalency points are marked on the figure (vertical grey bar). (b, c; top) Comparison of the expected catalyst potential, $E_{\mathrm{LSV}}$ (blue bar), from the current equivalency point and the measured catalyst potential, $E_{\text {cat }}$ (green bar) during thermochemical oxidation of FA in (b) GD and (c) nGD reaction modes. (b, c; bottom) Comparison of the measured specific reaction rates during electrochemically-driven FAOR at $E_{\text {cat }}$ (red bar) and thermochemical FA oxidation (orange bar) in (b) GD and (c) nGD reaction modes. (d) LSVs of FAOR and ORR with different concentrations of FA $(0.1 \mathrm{M}$ and $0.5 \mathrm{M})$, scan rate: $10 \mathrm{mV} \mathrm{s}^{-1}$. (e, f; top) Comparison of the expected catalyst potential, $E_{\mathrm{LSV}}$ (blue bar), from the current equivalency point and the measured catalyst potential, $E_{\text {cat }}$ (green bar) during thermochemical oxidation of FA with (e) $0.5 \mathrm{M}$ and (f) $0.1 \mathrm{M}$ of FA. (e, f; bottom) Comparison of the measured specific reaction rates during electrochemically-driven FAOR at $E_{\text {cat }}$ (red bar) and the thermochemical FA oxidation (orange bar) with (e) $0.5 \mathrm{M}$ and (f) $0.1 \mathrm{M}$ of FA. The recorded currents in (a) and (d) are normalized by the geometric surface areas of the electrodes contacted with reaction solutions. Error bars indicate standard errors obtained from 3 or more independent replicates. 
Using the same model reaction, Pt-catalyzed aerobic FA oxidation, we first examined the impact of restricted mass transport of $\mathrm{O}_{2}$ (Fig. 3a, 3b, and 3c) by comparing electrochemical and thermochemical reactivity on catalyst films interfaced with the $\mathrm{O}_{2}$ stream with (GD) and without (nGD) a gas diffusion layer. During nGD conditions, the catalyst layers were submerged entirely within the aqueous solution, thereby diminishing the $\mathrm{O}_{2}$ flux to the catalyst via a direct transport path between the reaction headspace and the catalyst film (see Fig. S3 for further details). Unsurprisingly, the measured thermochemical reaction rate of $3.1 \pm 0.3 \mathrm{mmol}_{\mathrm{CO}_{2}} \mathrm{hr}^{-1}$ $\mathrm{mg}_{\mathrm{Pt}}{ }^{-1}$ under GD mode, declines dramatically to $0.14 \pm 0.004 \mathrm{mmol}_{\mathrm{CO}} \mathrm{hr}^{-1} \mathrm{mg}_{\mathrm{Pt}}{ }^{-1}$ under nGD condition (Fig. 3c). However, the SC model provides a more detailed picture of how the overall reaction is impacted by this imposed limitation on $\mathrm{O}_{2}$ transport. As seen in Fig. 3a, the inhibited $\mathrm{O}_{2}$ transport in nGD mode dramatically alters the ORR polarization curve (blue) but leaves the $\mathrm{O}_{2}$-independent FAOR polarization curve largely unchanged (red). Consequently, the current equivalency point, $E_{\mathrm{LSV}}$, shifts substantially lower to $0.23 \mathrm{~V}$, and this predicted value is again in line with the equilibrated potential, $E_{\text {cat }}, 0.21 \mathrm{~V}$, measured during thermochemical oxidation in nGD mode (Fig. 3c, top). At this lowered potential, the ORR polarization curve displays a clear transport limited plateau, indicating that the reaction rate is solely influenced by change in $\mathrm{O}_{2}$ flux, but not changes in the intrinsic kinetics of the half-reactions (Fig. 3a). In line with this expectation, the measured mixed potential is dependent on solution convection, varying with changes in the stirring rate (Fig. S4). While this extreme case of severe transport limitations in a relatively simple reaction is easy to analyze without applying the SC model, we stress that the information provided by the electrochemical analysis of each constitutive half reaction aids the analysis of more complex situations in which one or both reactions are subject to (mixed) activation and transport control.

We next investigated the impact of FA concentration (Fig. 3d, 3e and 3f). As expected, decreasing its concentration from $0.5 \mathrm{M}$ to $0.1 \mathrm{M}$ attenuates the FAOR polarization curve (Fig. 3d). Consequently, the expected current equivalency point $\left(E_{\mathrm{LSV}}\right)$ shifts higher to $0.78 \mathrm{~V}$, which is in good agreement with the measured catalyst potential of $0.81 \mathrm{~V}$ during the thermochemical reaction (Fig. 3f, top). As observed above, the rate of electrochemically driven FAOR of $1.3 \pm 0.09 \mathrm{mmol}_{\mathrm{CO}_{2}} \mathrm{hr}^{-1} \mathrm{mg}_{\mathrm{Pt}}{ }^{-1}$ measured at this mixed potential again closely matches the measured rate of the thermochemical aerobic oxidation, $1.2 \pm 0.13 \mathrm{mmol}_{\mathrm{CO}_{2}} \mathrm{hr}^{-1} \mathrm{mg}_{\mathrm{Pt}}{ }^{-1}$. (Fig. 3f, bottom). Simply comparing the thermochemical reaction rates, $1.2 \mathrm{mmol}_{\mathrm{CO}_{2}} \mathrm{hr}^{-1} \mathrm{mg}_{\mathrm{Pt}^{-1}}$ and $3.1 \mathrm{mmol}_{\mathrm{CO}_{2}} \mathrm{hr}^{-1} \mathrm{mg}_{\mathrm{Pt}^{-1}}$, at $0.1 \mathrm{M}$ and $0.5 \mathrm{M}^{-1}$ FA, respectively, yields a fractional reaction order in FA of $\sim 0.6$. Non-integer reaction orders are commonplace in many heterogeneous catalytic reactions and are often attributed to non-Langmuirian adsorption and/or site saturation effects. For complex reactions like aerobic oxidation, co-adsorbate interactions between, for example, $\mathrm{O}_{2}$ and the substrate, can lead to non-Langmuirian adsorption and attenuate substrate reaction orders. ${ }^{25,26,27,28,29}$ The SC model provides insight into the origin of the observed fractional order and the differential contributions to it from each half reaction. In particular, comparing the FA polarization curves at both concentrations (Fig. 3d) reveals that (a) the FAOR half reaction, by itself, displays a $\sim 0.5$ reaction order in the potential region of interest in the absence of $\mathrm{O}_{2}$ and (b) the shallow slope of the FA polarization curve makes it weakly sensitive to small changes in $E_{\text {cat }}$ Thus, while the equivalency potential point (and $E_{\text {cat }}$ ) moves more positive by $\sim 0.04 \mathrm{~V}$, the observed reaction order for thermochemical aerobic oxidation can be largely accounted for by the intrinsic order of the FAOR half-reaction, rather than co-adsorbate interactions with $\mathrm{O}_{2}$ or ORR intermediates. As this discussion highlights, the analysis of the electrochemical kinetics of each constitutive half-reactions can provide valuable complementary mechanistic insight alongside classical mechanistic studies of the overall transformation.

\section{The short-circuit model explains trends in catalyst materials}


With the foregoing understanding of how the SC framework applies to FA oxidation under varying reaction conditions, we next examined its general applicability across a variety of catalyst materials (Fig. 4). First, we studied how the SC model predicts and explains the impact of varying catalyst composition. Specifically, we investigate thermochemical and electrochemical reactivity of $\mathrm{PtRu}(1: 1$ atomic ratio) alloy catalysts (PtRu/C) for FA oxidation in comparison to Pt by itself (Pt/C) (Fig. 4a, 4b, and 4c). Relative to Pt, PtRu alloy composites are known to exhibit improved electrocatalytic performance towards oxidation of various substrates, including FA, CO, and alcohols. ${ }^{30}$ Exhaustive studies have found that $\mathrm{Ru}$, by itself, has low activity, but that it acts a powerful promoter of the native oxidation electrocatalysis activity of $\mathrm{Pt}^{30}$ Consistent with this understanding, the recorded FAOR curve of $\mathrm{PtRu} / \mathrm{C}$ normalized by Pt catalyst loading displays higher current density than that of $\mathrm{Pt} / \mathrm{C}$ at moderate overpotentials $(>0.55 \mathrm{~V})$ (Fig. 4a). Despite the appreciably higher FAOR ratio rate, the thermochemical rate with $\mathrm{PtRu} / \mathrm{C}$ catalyst $\left(2.8 \pm 0.1 \mathrm{mmol}_{\mathrm{CO}_{2}} \mathrm{hr}^{-1} \mathrm{mg}_{\mathrm{Pt}}{ }^{-1}\right)$ is slightly lower that the rate of the Pt/C catalyzed reaction $\left(3.1 \pm 0.3 \mathrm{mmol}_{\mathrm{CO}_{2}} \mathrm{hr}^{-1} \mathrm{mg}_{\mathrm{Pt}^{-1}}\right)$ (Fig. $\mathbf{4 b}$ and $\mathbf{4 c}$, bottom). This seemingly counter-intuitive observation is readily explained by the $\mathrm{SC}$ framework. Although the $\mathrm{PtRu} / \mathrm{C}$ catalyst exhibits higher FAOR current,
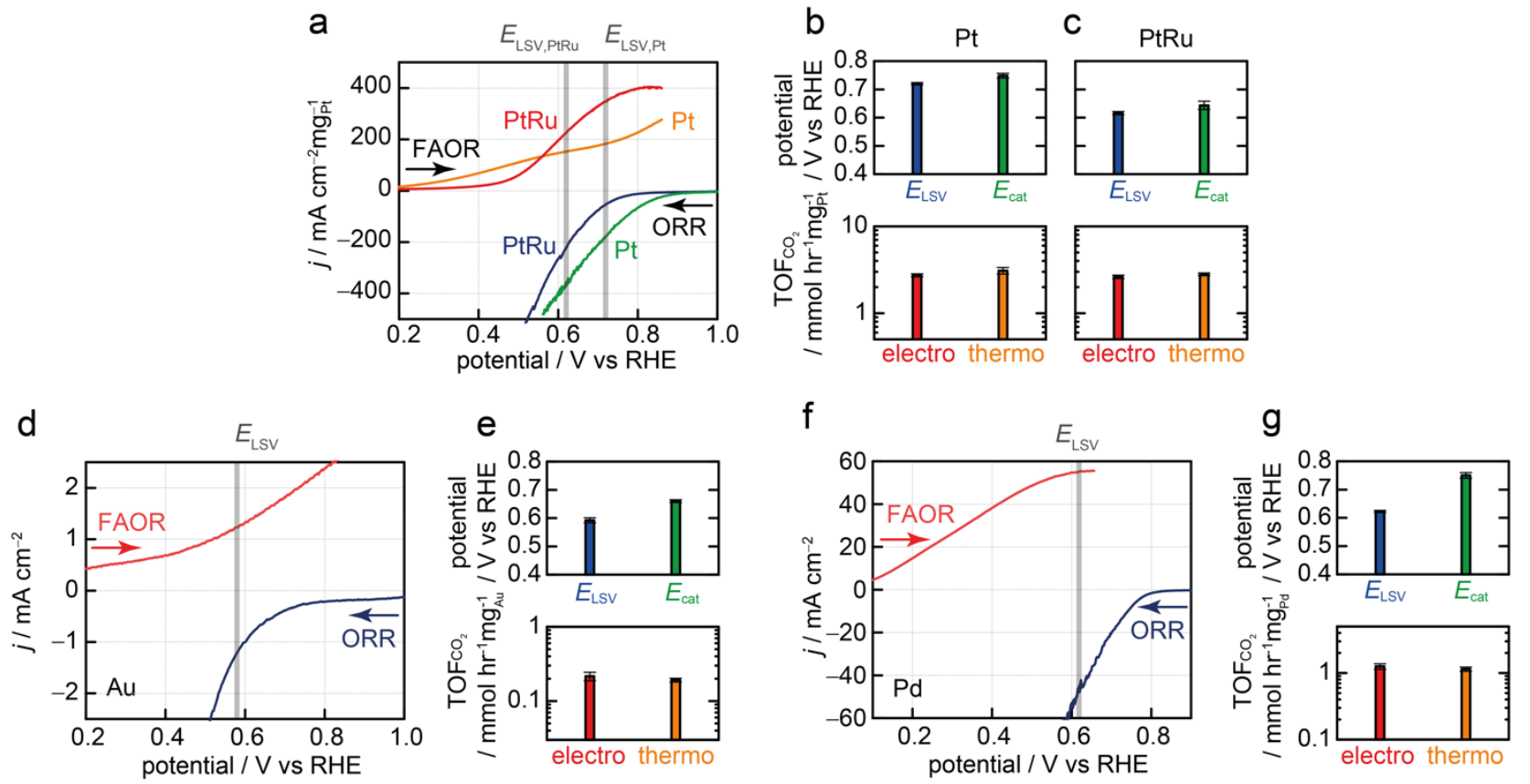

Fig. 4. (a) FAOR and ORR LSVs with different catalyst compositions (Pt/C and $\mathrm{PtRu} / \mathrm{C})$ at $\mathrm{pH} 1\left(0.1 \mathrm{M} \mathrm{HClO}_{4}\right)$, scan rate: $10 \mathrm{mV} \mathrm{s}{ }^{-1}$. The recorded currents are normalized by geometric areas of electrodes and catalyst loadings in Pt mass. The current equivalency points are marked on the figure (vertical grey bar). (b,c; top) Comparison of the expected catalyst potential, $E_{\mathrm{LSV}}$ (blue bar), from the current equivalency point and the measured catalyst potential, $E_{\text {cat }}$ (green bar) during thermochemical oxidation of FA with (b) Pt/C and (c) $\mathrm{PtRu} / \mathrm{C}$. (b,c; bottom) Comparison of the measured specific reaction rates during electrochemically-driven FAOR at $E_{\text {cat }}($ red bar) and thermochemical oxidation of FA (orange bar) with (b) $\mathrm{Pt} / \mathrm{C}$ and (c) PtRu/C. (d) FAOR and ORR LSVs of $\mathrm{Au} / \mathrm{C}$ at pH $1(0.1 \mathrm{M} \mathrm{HClO}$ ), scan rate: $10 \mathrm{mV} \mathrm{s}^{-1}$. (e; top) Comparison of the expected catalyst potential, $E_{\mathrm{LSV}}$ (blue bar), from the current equivalency point and measured catalyst potential, $E_{\text {cat }}$ (green bar) during thermochemical oxidation of FA. (e; bottom) Comparison of the measured specific reaction rates during electrochemically-driven FAOR at $E_{\text {cat }}$ (red bar) and thermochemical oxidation of FA (orange bar). (f) FAOR and ORR LSVs of $\mathrm{Pd} / \mathrm{C}$ at $\mathrm{pH} 1\left(0.1 \mathrm{M} \mathrm{HClO}_{4}\right)$, scan rate: $10 \mathrm{mV} \mathrm{s}^{-1}$. (g; top) Comparison of the expected catalyst potential, $E_{\mathrm{LSV}}$ (blue bar), from the current equivalency point and measured catalyst potential, $E_{\text {cat }}$ (green bar) during thermochemical oxidation of FA. (g; bottom). Comparison of the measured specific reaction rates during electrochemically-driven FAOR at $E_{\mathrm{cat}}$ (red bar) and thermochemical oxidation of FA (orange). The recorded currents in (d) and (f) are normalized by geometric areas of electrodes. In (a), (d), and (f), $0.5 \mathrm{M}$ of FA was used for FAOR. Error bars indicate standard errors obtained from 3 or more independent replicates.

it displays substantially lower ORR efficiency than Pt (Fig. 4a) with an onset of $10 \mathrm{~mA} \mathrm{~cm}^{-2} \mathrm{mg}_{\mathrm{P}_{\mathrm{t}}}{ }^{-1}$ requiring an additional $\sim 0.1 \mathrm{~V}$ overpotential. This relative loss in ORR activity of the PtRu/C catalyst counteracts its enhanced activity for FAOR. These countervailing contributions manifest in a significant lowering of the current equivalency point $\left(E_{\mathrm{LSV}}\right)$ to $0.62 \mathrm{~V}$ for PtRu/C from $0.75 \mathrm{~V}$ for $\mathrm{Pt} / \mathrm{C}$. As in the previous examples, the predicted potential is in line with the measured $E_{\text {cat }}$ of $0.64 \mathrm{~V}$ during thermochemical catalysis (Fig. 4b and 4c, top).

Employing the same methods as above, we examined aerobic FA oxidation on different metal-based catalysts: Au/C (Fig. 4d and 4e) and $\mathrm{Pd} / \mathrm{C}(\mathbf{F i g} . \mathbf{4 f}$ and $\mathbf{4 g})$. For these metals, polarization curves of FAOR and ORR reach their respective current equivalency points $\left(E_{\mathrm{LSV}}\right)$ of $0.59 \mathrm{~V}$ for $\mathrm{Au} / \mathrm{C}($ Fig. $4 \mathrm{~d})$ and $0.62 \mathrm{~V}$ for Pd/C (Fig. 4f). These predicted values exhibit appreciable deviations from the catalyst potentials $\left(E_{\text {cat }}\right), 0.66 \mathrm{~V}$ for Au/C (Fig. 4e, top) and $0.75 \mathrm{~V}$ for $\mathrm{Pd} / \mathrm{C}$ (Fig. 4 g, top), measured during the thermochemical oxidation of FA. Nonetheless, at the measured catalyst potentials $\left(E_{\mathrm{cat}}\right)$, the steady-state rates of electrochemically driven FAOR of $0.22 \pm 0.03 \mathrm{mmol}_{\mathrm{CO}} \mathrm{hr}^{-1} \mathrm{mg}_{\mathrm{Au}}{ }^{-1}$ for $\mathrm{Au} / \mathrm{C}$ and of $1.26 \pm 0.13 \mathrm{mmol}_{\mathrm{CO}_{2}} \mathrm{hr}^{-1} \mathrm{mg}_{\mathrm{Pd}}{ }^{-1}$ for $\mathrm{Pd} / \mathrm{C}$ matches the measured rates of the thermochemical aerobic oxidation, $0.19 \pm 0.01 \mathrm{mmol}_{\mathrm{CO}_{2}} \mathrm{hr}^{-1} \mathrm{mg}_{\mathrm{Au}^{-1}}{ }^{-1}$ for Au/C (Fig. 4e, bottom) and $1.15 \pm 0.08 \mathrm{mmol}_{\mathrm{CO}_{2}} \mathrm{hr}^{-1} \mathrm{mg}_{\mathrm{Pd}^{-1}}$ for $\mathrm{Pd} / \mathrm{C}$ (Fig. 4g, bottom).

The deviations between $E_{\mathrm{LSV}}$ and $E_{\text {cat }}$ for these two catalysts can be explained by slow deactivation of FAOR catalysis on a timescale longer than the transient LSV measurements (scan rate: $10 \mathrm{mV} \mathrm{s}^{-1}$ ). Indeed, chronoamperometric FAOR traces of Au/C (Fig. S5) and 
$\mathrm{Pd} / \mathrm{C}$ catalysts (Fig. S6) display substantial attenuation in current over the timescale of several minutes, significantly longer than the $\sim 1$ min time scale of the entire LSV sweep. This longer-term deactivation serves to attenuate the FAOR rate and correspondingly moves the current equivalency points to more positive values. In line with this reasoning, we observe at the $E_{\text {cat }}$ values measured during thermochemical catalysis shift positively over a similar timescale (Fig. S7 and S8). Even slower scan LSVs or stepped chronoamperometry data would better capture these longer time scale transients and, better predict the $E_{\text {cat }}$. Notwithstanding, the foregoing analysis highlights the utility of the SC model in quantifying catalyst dynamics over diverse timescales.

Together, the data from this and the previous section indicate that the SC framework provides predictive insights into trends in net thermochemical aerobic oxidation reactivity across both reaction variables and catalyst materials.

\section{The short-circuit model applies generally across small molecule substrates}

The foregoing data evincing the utility of the SC model for FA oxidation catalysis motivated us to examine whether SC behavior prevails across other small-molecule substrates. Thus, in this section, we apply the SC model to analyze Pt/C catalyzed aerobic oxidation of methanol, ethanol, and propanol (Fig. 5). Importantly, for each of the substrates, Pt/C displays known electrochemical reactivity for the methanol oxidation reaction (MOR), ethanol oxidation reaction (EOR), and propanol oxidation (POR). ${ }^{31,32,33,34,35}$ Therefore, we postulate that these catalyzed half-reactions combine with ORR to furnish net thermochemical aerobic oxidation. For thermochemical methanol oxidation (Fig. 5a), independently measured MOR and ORR polarization curves reach the expected current equivalency point $\left(E_{\mathrm{LSV}}\right)$ of $0.73 \mathrm{~V}$ and this predicted value is in line with the measured equilibrated potential, $E_{\text {cat }}, 0.76 \mathrm{~V}$, during the thermochemical reaction (Fig. 5b, top). For both electrochemical and thermochemical methanol oxidation, $\mathrm{CO}_{2}$ was found to be a sole product and the rate of electrochemically driven MOR at the measured mixed potential, $1.13 \pm 0.09 \mathrm{mmol}_{\mathrm{CO}_{2}} \mathrm{hr}^{-1} \mathrm{mg}_{\mathrm{Pt}}{ }^{-1}, \mathrm{shows}$ good agreement with the measured rate of $1.26 \pm 0.06$ mmol $_{\mathrm{CO}_{2}} \mathrm{hr}^{-1} \mathrm{mg}_{\mathrm{Pt}^{-1}}$ during thermochemical methanol oxidation (Fig. 5b, bottom). As such, these quantitative analyses on both catalyst potentials and reaction rates corroborate that thermochemical methanol oxidation proceeds via coupling of electrochemical MOR and ORR half reactions. 
The applicability of the SC model further extends to thermochemical oxidation of ethanol and propanol. In these two cases, ORR polarization curves reach the expected current equivalency $E_{\mathrm{LSV}}$ point of $0.78 \mathrm{~V}$ for ethanol oxidation $(\mathbf{F i g} . \mathbf{5 c})$ and $0.80 \mathrm{~V}$ for propanol oxidation (Fig. 5f), which are indeed in line with the equilibrated potentials, $0.76 \mathrm{~V}$ (Fig. 5d, top), and $0.77 \mathrm{~V}$ (Fig. 5g, top), during thermochemical oxidation of ethanol and propanol, respectively. Notably, both electrochemical and thermochemical oxidation produces a mixture of ethanal and acetic acid for ethanol oxidation and propanal and propionic acid for propanol oxidation. For ethanol oxidation, electrochemically driven EOR at the $E_{\text {cat }}$ in the absence of $\mathrm{O}_{2}$, gives rise to the nearly identical partial reaction rates for each product $\left(0.25 \pm 0.02 \mathrm{mmol}_{\text {ethanal }} \mathrm{hr}^{-1} \mathrm{mg}_{\mathrm{Pt}}{ }^{-1}\right.$ and $\left.0.27 \pm 0.01 \mathrm{mmol}_{\text {acetic acid }} \mathrm{hr}^{-1} \mathrm{mg}_{\mathrm{P}}{ }^{-1}\right)$ as is observed for the thermochemical reaction $\left(0.31 \pm 0.05 \mathrm{mmol}_{\text {ethanal }} \mathrm{hr}^{-1} \mathrm{mg}_{\mathrm{Pt}}{ }^{-1}, 0.34 \pm 0.11 \mathrm{mmol}_{\text {acetic acid }} \mathrm{hr}^{-1} \mathrm{mg}_{\mathrm{pt}}{ }^{-1}\right)$ (Fig. 5d, bottom). Consequently, at $\sim 1-2 \%$ substrate conversion, we observe a selectivity of $48 \%$ for ethanal (52\% for acetic acid) during electrochemically driven EOR, which is identical to the selectivity of $48 \%$ for ethanal (52\% for acetic acid) during thermochemical oxidation of ethanol (Fig. 5e) at the same
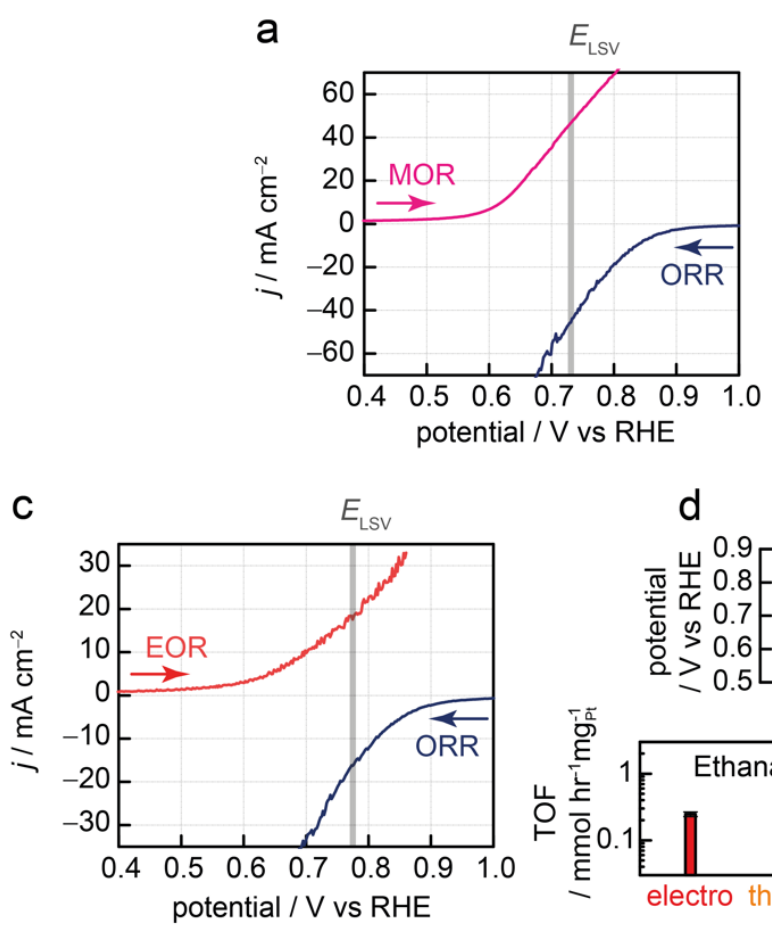

f

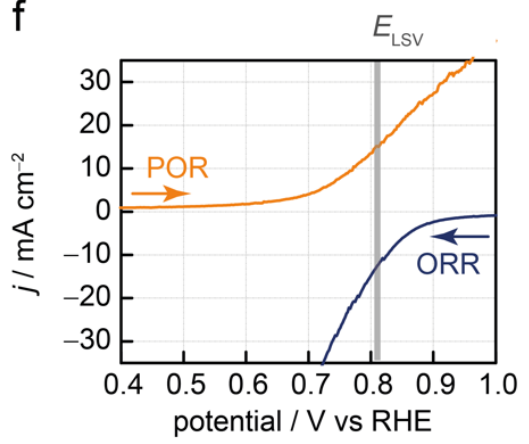

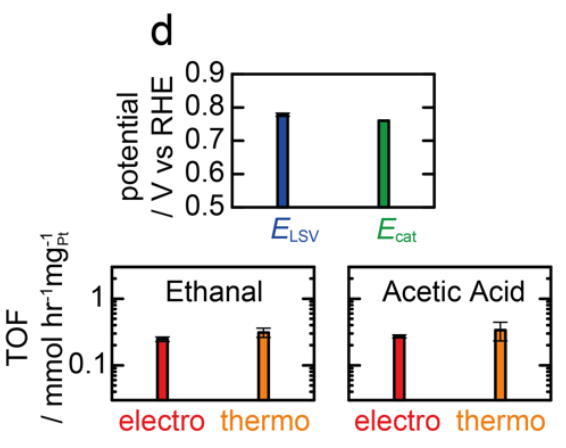

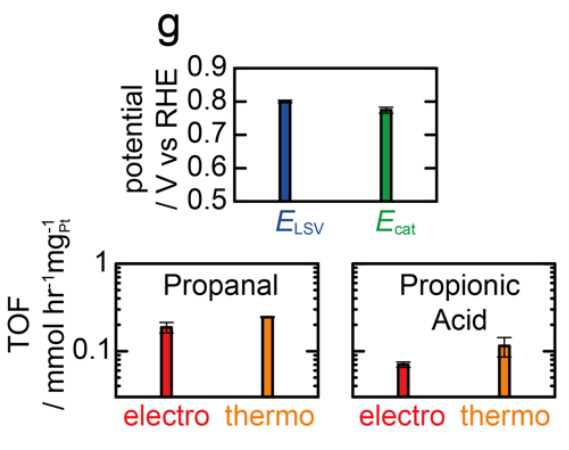

b

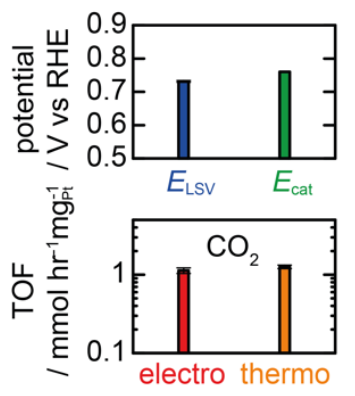

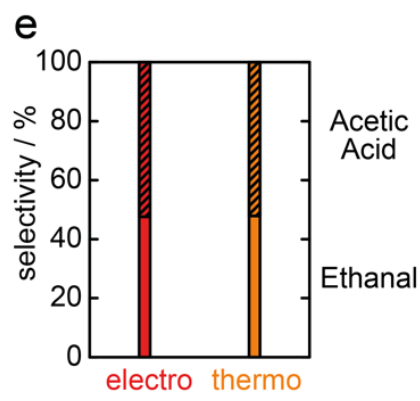

$\mathrm{h}$

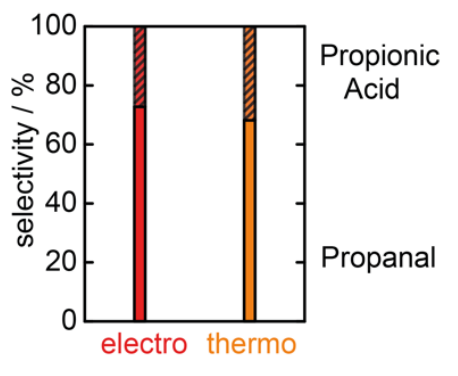

Fig. 5. (a) MOR and ORR LSVs of Pt/C at pH $1\left(0.1 \mathrm{M} \mathrm{HClO}_{4}\right)$, scan rate: $10 \mathrm{mV} \mathrm{s}^{-1}$. (b; top) Comparison of the expected catalyst potential, $E_{\mathrm{LSV}}\left(\right.$ blue bar), from the current equivalency point and the measured catalyst potential, $E_{\mathrm{cat}}(\mathrm{Green}$ bar) during thermochemical oxidation of methanol. (b; bottom) Comparison of the measured specific reaction rates during electrochemically-driven MOR at $E_{\text {cat }}$ (red bar) and thermochemical oxidation of methanol (orange bar). (c) EOR and ORR LSVs of Pt/C at pH 1 ( $0.1 \mathrm{M} \mathrm{HClO}_{4}$ ), scan rate: $10 \mathrm{mV} \mathrm{s}^{-1}$. (d; top) Comparison of the expected catalyst potential, $E_{\mathrm{LSV}}$ (blue bar), from the current equivalency point and the measured catalyst potential, $E_{\mathrm{cat}}$ (green bar) during thermochemical oxidation of ethanol. (d; bottom) Comparison of the measured specific reaction rates for each product (ethanal, left, and acetic acid, right) during electrochemically-driven EOR at Ecat (red bar) and thermochemical oxidation of methanol (orange bar). (e) Comparison of the product selectivity during electrochemically-driven EOR and thermochemical oxidation of ethanol. (f) POR and ORR LSVs of Pt/C at $\mathrm{pH} 1\left(0.1 \mathrm{M} \mathrm{HClO}_{4}\right)$, scan rate: $10 \mathrm{mV} \mathrm{s}^{-1}$. (g; top) Comparison of the expected catalyst potential, $E_{\mathrm{LSV}}$ (blue bar), from the current equivalency point and the measured catalyst potential, $E_{\text {cat }}$ (green bar) during thermochemical oxidation of propanol. (g; bottom) Comparison of the measured specific reaction rates for each product (propanal, left, and propionic acid, right) during electrochemically-driven POR at $E_{\text {cat }}$ (red bar) and thermochemical oxidation of propanol (orange bar). (h) Comparison of the product selectivity during electrochemically-driven POR and thermochemical oxidation of propanol. The recorded currents in (a), (c), and (f) are normalized by the geometric areas of electrodes. A $0.5 \mathrm{M}$ substrate (methanol, ethanol, and propanol) concentration was used for each experiment. Error bars indicate standard errors obtained from 3 or more independent replicates. 
$\sim 1-2 \%$ conversion. Similarly, for propanol oxidation, electrochemically driven POR at the $E_{\text {cat }}$ in the absence of $\mathrm{O}_{2}$, exhibits partial reaction rates for each product $\left(0.19 \pm 0.03 \mathrm{mmol}_{\text {propanal }} \mathrm{hr}^{-1} \mathrm{mg}_{\mathrm{Pt}}{ }^{-1}\right.$ and $\left.0.07 \pm 0.005 \mathrm{mmol}_{\text {propionic acid }} \mathrm{hr}^{-1} \mathrm{mg}_{\mathrm{Pt}}{ }^{-1}\right)$ in line with those observed for the thermochemical reaction $\left(0.25 \pm 0.003 \mathrm{mmol}_{\text {propanal }} \mathrm{hr}^{-1} \mathrm{mg}_{\mathrm{Pt}}{ }^{-1}\right.$, and $\left.0.11 \pm 0.03 \mathrm{mmol}_{\mathrm{propionic}_{\text {acid }}} \mathrm{hr}^{-1} \mathrm{mg}_{\mathrm{Pt}}{ }^{-1}\right)($ Fig. $\mathbf{5 g}$, bottom). Thus, at $\sim 1 \%$ substrate conversion, we observed selectivity of $72 \%$ for propanal ( $27 \%$ for propionic acid) during electrochemically driven POR, which closely matches the selectivity of $68 \%$ for propanal (32\% for propionic acid) during thermochemical oxidation of propanol (Fig. 5h) at the same $\sim 1 \%$ conversion. Given that electrochemical reaction selectivity is known to be dependent on potential, ${ }^{36,37}$, and $E_{\text {cat }}$ can be systematically varied by changing the reaction variables (see above), the SC model can be used to predict ideal reaction conditions to favor a given product. More broadly, the above studies suggest that the SC model may have general applicability for aerobic oxidations across a wide variety of substrates and could provide a rational basis for understanding and improving thermochemical liquid-phase catalysis.

The short-circuit model provides insight into the inherent pH-dependence of aerobic oxidation catalysis

Proton activity $($ or $\mathrm{pH})$ has been recognized to play a particularly important role in defining the rate and selectivity of aerobic oxidation reactions on solid catalysts. ${ }^{3,38,39,40}$ In particular, it has been found that many catalysts display poor or negligible aerobic oxidation activity in acidic media, but display dramatically promoted activity in alkaline reaction conditions ( $\mathrm{pH} 13$ or 14). ${ }^{41,42}$ Despite substantial mechanistic effort, the origin of this strong $\mathrm{pH}$ dependence still remains the subject of debate. ${ }^{38,43,44}$ Notably, whereas protons are not obvious reaction participants in the overall thermochemical reaction, they are clearly reaction participants in the electrochemical half reactions of alcohol oxidation and ORR, both of which are known to display pronounced pH-dependent kinetics. ${ }^{41,42,43,44,33}$ Thus, we postulated that the net $\mathrm{pH}$ dependence of the thermochemical reaction simply reflects the compounded $\mathrm{pH}$ dependence of each individual half reactions. To test this hypothesis, we examined aerobic oxidation of ethanol on both $\mathrm{Au} / \mathrm{C}(\mathbf{F i g}$. 6a, 6b, and $\mathbf{6 c})$ and $\mathrm{Pd} / \mathrm{C}$ catalysts (Fig. 6d, 6e, and 6f) under acidic, $\mathrm{pH} 1\left(0.1 \mathrm{M} \mathrm{HClO}_{4}\right)$, and alkaline, $\mathrm{pH} 13(0.1 \mathrm{M} \mathrm{KOH})$, reaction conditions. Partially oxidized products, ethanal and acetic acid, were found to be the sole products detected during these reactions in all cases.
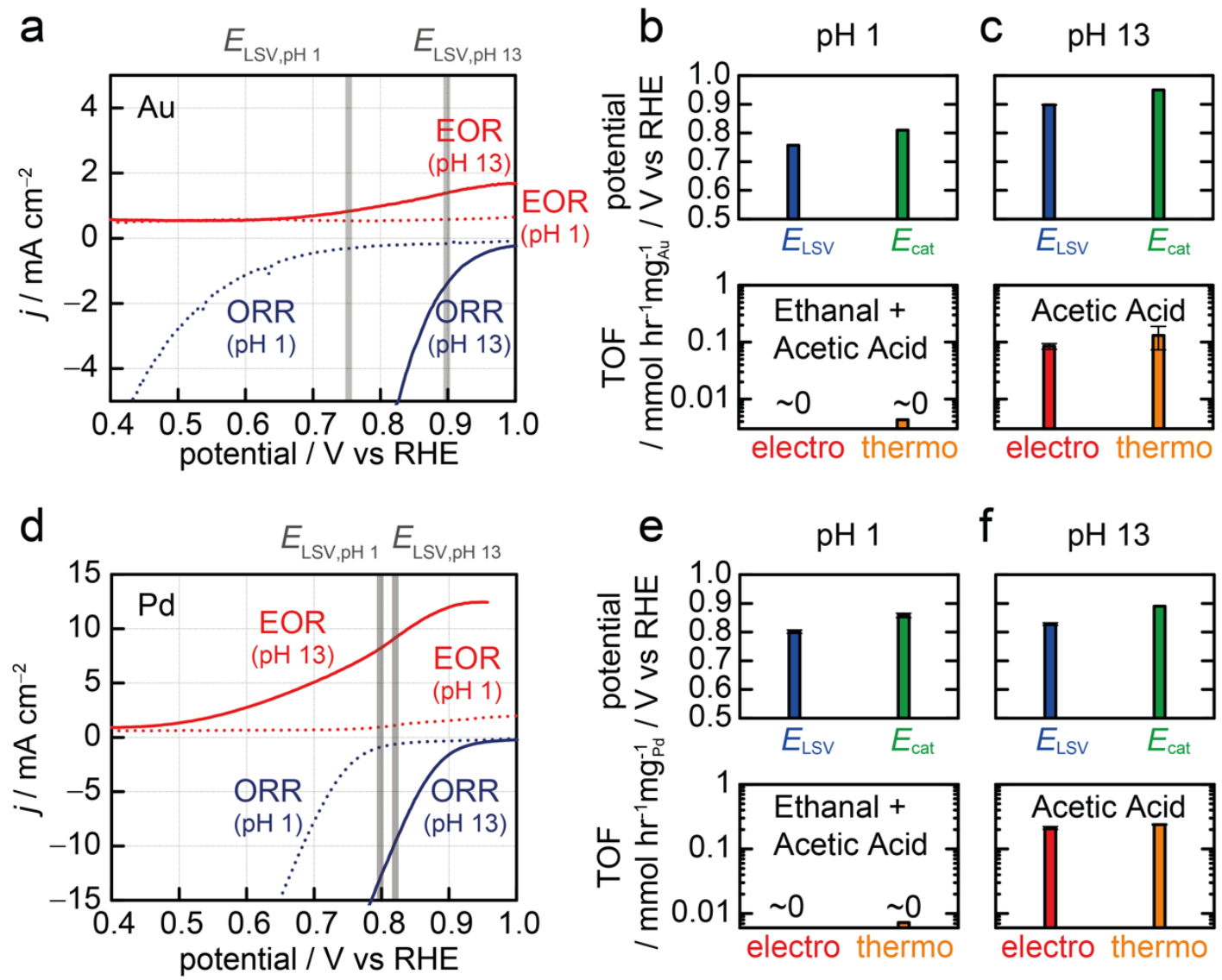

Fig. 6. (a) EOR and ORR LSVs of $\mathrm{Au} / \mathrm{C}$ at $\mathrm{pH} 1\left(0.1 \mathrm{M} \mathrm{HClO}_{4}\right)$ (dotted curve) and pH $13(0.1 \mathrm{M} \mathrm{KOH})$ (solid curve). (b,c; top) Comparison of the expected catalyst potential, $E_{\mathrm{LSV}}$ (blue bar) from the current equivalency point and the measured catalyst potential, $E_{\mathrm{cat}}$ (green bar) during thermochemical oxidation of ethanol at $(\mathbf{b}) \mathrm{pH} 1$ and $(\mathbf{c}) \mathrm{pH}$ 13. (b,c; bottom) Comparison of the measured specific reaction rates during electrochemically-driven $\mathrm{EOR}$ at $E_{\text {cat }}$ (red bar) and thermochemical oxidation of ethanol (orange bar) at (b) $\mathrm{pH} 1$ and (c) $\mathrm{pH}$ 13. (d) EOR and ORR LSVs of $\mathrm{Pd} / \mathrm{C}$ at pH 1 (0.1 $\left.\mathrm{M} \mathrm{HClO}_{4}\right)$ (dotted curve) and $\mathrm{pH} 13(0.1 \mathrm{M} \mathrm{KOH})$ (solid curve). (e,f; top) Comparison of the expected catalyst potential, $E_{\mathrm{LSV}}$ (blue bar), from the current equivalency point and the measured catalyst potential, $E_{\text {cat }}$ (green bar) during thermochemical oxidation of ethanol at (e) $\mathrm{pH} 1$ and (f) $\mathrm{pH}$ 13. (e,f; bottom) Comparison of the measured specific reaction rates during electrochemically-driven EOR at $E_{\text {cat }}$ (red bar) and thermochemical oxidation of ethanol (orange bar) at (e) $\mathrm{pH} 1$ and (f) $\mathrm{pH}$ 13. The recorded currents in (a) and (d) are normalized by the geometric areas of electrodes. A $0.5 \mathrm{M}$ ethanol concentration was used in these studies. Error bars indicate standard errors obtained from 3 or more independent replicates. 
Consistent with previous reports ${ }^{4,7}$, we found no appreciable thermochemical reactivity with both catalysts at $\mathrm{pH} 1\left(<0.01 \mathrm{mmol} \mathrm{eth}_{\text {- }}\right.$ anal+acetic acid $\mathrm{hr}^{-1} \mathrm{mg}_{\text {metal }}{ }^{-1}$ ) (Fig. 6b and 6e, bottom), whereas a substantial and selective promotion of ethanol oxidation to acetic acid was observed at $\mathrm{pH} 13\left(0.08 \pm 0.01 \mathrm{mmol}_{\text {acetic acid }} \mathrm{hr}^{-1} \mathrm{mg}_{\mathrm{Au}}{ }^{-1}\right.$ and $\left.0.21 \pm 0.01 \mathrm{mmol}_{\text {acetic acid }} \mathrm{hr}^{-1} \mathrm{mg}_{\mathrm{Pd}}{ }^{-1}\right)$ (Fig. 6c and Fig. 6f, bottom).

This thermochemical reactivity trend with $\mathrm{pH}$ is fully captured in the corresponding $\mathrm{pH}$ dependence of EOR and ORR. Specifically, the ORR of $\mathrm{Au} / \mathrm{C}$ is found to be sluggish at $\mathrm{pH} 1$, with an onset of $0.3 \mathrm{~mA} \mathrm{~cm}{ }^{-2}$ at $0.75 \mathrm{~V}$ (Fig. 6a, blue, dotted curve). In contrast, under alkaline conditions, Au-catalyzed ORR is significantly promoted with an onset of $0.98 \mathrm{~V}$ at the same current density (Fig. 6a, blue, solid curve). For the EOR half reaction, Au is entirely inactive over a wide potential range in acid (Fig. 6a, red, dotted curve), but displays appreciable activity with an onset of $\sim 0.65 \mathrm{~V}$ in alkaline media (Fig. 6a, red, solid curve). This dual promotion of EOR and ORR in alkaline media leads to a dramatic change in the predicted $E_{\mathrm{LSV}}$ from $0.76 \mathrm{~V}$ in acidic media, to $0.90 \mathrm{~V}$ in alkaline media. Both of these predicted $E_{\mathrm{LSV}}$ values closely match the recorded $E_{\text {cat }}$ during catalysis in the two reaction media (Fig. 6b and $6 \mathbf{c}$, top). For $\mathrm{Pd} / \mathrm{C}$, the ORR is enhanced as well (Fig. 6d, blue solid vs dotted), but to a lesser extent than for Au/C. However, Pd/C experiences a much greater enhancement in EOR between the two reaction media (Fig. 6d, red solid vs dotted). Because of the shallower polarization slope for the EOR, the combined effects of EOR and ORR promotion on Pd leads to a smaller predicted change in $E_{\mathrm{LSV}}$ of 0.02 $\mathrm{V}$ despite the large $\mathrm{pH}$ change and this small change also matches the shift of $0.03 \mathrm{~V}$ observed experimentally in the $E_{\text {cat }}$ during thermochemical catalysis on Pd. We stress that the similarity in potentials at the pH extremes (1 and 13) arises only when referenced to the reversible hydrogen electrode (RHE) scale which already accounts for the enormous change in proton activity. Indeed, on a $\mathrm{pH}$-independent reference scale, the catalyst potential is shifted by an additional $0.71 \mathrm{~V}$ between acidic and alkaline media, further highlighting the direct influence of proton activity on the overall thermochemical reaction. As in all prior cases, electrochemical polarization of the catalyst at $E_{\text {cat }}$ in the absence of $\mathrm{O}_{2}$, gives rise to product formation with selectivity and rate that matches that observed under thermochemical turnover (Fig. 6b, 6c, $6 \mathbf{e}$ and $\mathbf{6 f}$, bottom), further evincing the inherently electrochemical nature of the $\mathrm{pH}$-dependent reactivity trend. In aggregate, the above analysis within the SC framework indicates that for the Au catalyst, the aggregate $\mathrm{pH}$ dependence is attributed to contributions from both half reactions, whereas, for Pd catalyst, the $\mathrm{pH}$ dependence of EOR primarily drives the net $\mathrm{pH}$ dependence of thermochemical ethanol oxidation.

The foregoing analysis highlights that the net $\mathrm{pH}$-dependence of thermochemical aerobic oxidation can be broken down into intrinsic contributions from the $\mathrm{pH}$-dependence of each underlying half reaction. Indeed, the $\mathrm{pH}$-dependence of electrocatalytic reactions has been and remains a subject of vigorous research. ${ }^{45,39,46,47,48,49,50,51,52}$ In these studies, researchers have invoked $\mathrm{pH}$-dependent adsorption energies ${ }^{48,51}$, electric field strengths ${ }^{45,50,52}$, potentials of zero charge ${ }^{45,49,50}$, and water reorganization barriers ${ }^{45}$ as contributions to the $\mathrm{pH}$-dependence of a variety of half-reactions. Our studies imply that those same effects, with the additional contribution of varying mixed potentials, are relevant for thermochemical catalysis as well.

\section{Conclusions}

The foregoing studies establish a general framework for analyzing a variety of aqueous-phase aerobic oxidation reactions within the context of mixed-potential theory and provide strong evidence of the inherently electrochemical nature of this important class of aqueous-phase thermochemical catalytic reactions. Our principal findings are:
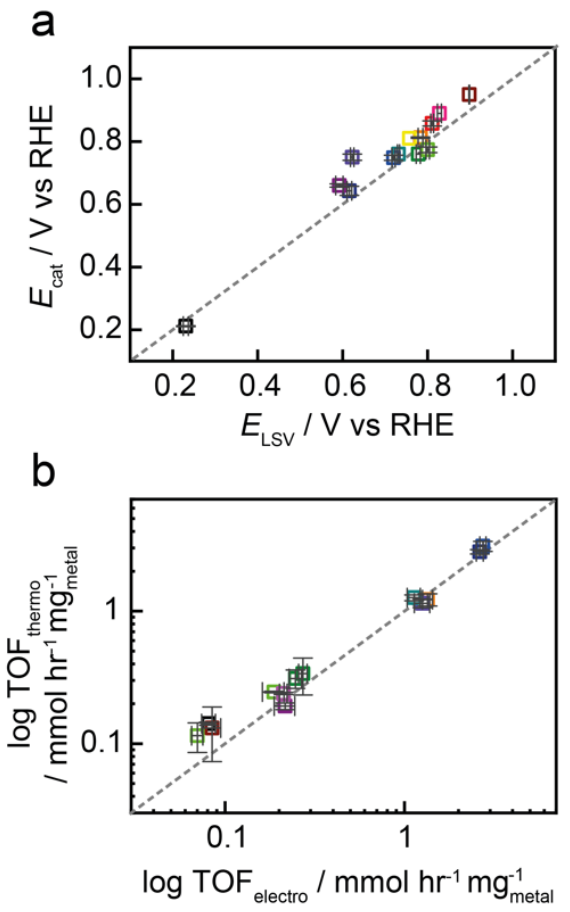

Fig. 7. (a) Comparison of expected catalyst potential $\left(E_{\mathrm{LSV}}\right)$ taken from the voltammetric current equivalency points vs the measured equilibrium catalyst potentials ( $\left.E_{\text {cat }}\right)$ for all reactions and conditions examined in this study. (b) Comparison of the electrochemically-driven TOF for substrate oxidation at $E_{\text {cat }}$ and the measured thermochemical TOF of aerobic oxidation for all reactions and conditions examined in this study. Dotted lines denoting perfect correspondence are provided as guides to the eye. 
- By collecting electrochemical and thermochemical data on common catalysts under identical reaction/transport environments, we find that the electrochemical polarization curves of ORR and the substrate oxidation half reaction closely predict the potential of the catalyst measured in operando during thermochemical catalysis across a range of catalysts, reactants, and reaction conditions (Fig. 7a). Slight deviations positive of the grey line likely arise from catalyst deactivation during steady-state operation that are not fully captured in the transient voltammograms. Nonetheless, the predictive power of the SC model sets the stage for its broad utility in catalyst discovery and mechanistic inquiry.

We find that driving the oxidation reaction electrochemically in the absence of $\mathrm{O}_{2}$ at the mixed potential leads to very similar rates and selectivities as for the thermochemical reaction (Fig. $7 \mathbf{b}$ ) in all cases. The correspondence in rates across a diverse range of $\mathrm{pHs}$, catalyst compositions, reactants, reaction conditions, and product selectivities strongly supports the notion that the role of $\mathrm{O}_{2}$ is solely as an electron scavenger that provides an incipient electrochemical driving force for substrate oxidation. Indeed, these findings narrow the scope of possible mechanisms for aerobic oxidation because the surface intermediates involved in the thermochemical reaction must also be accessible via electrochemical polarization.

The power of the short-circuit (SC) model to predict and explain catalyst performance and reactivity trends in aerobic oxidation across a wide array of variables highlights the utility of electrochemical studies in aiding the rational design of new and improved catalysts and systems for thermochemical aerobic oxidation. Furthermore, since the role of $\mathrm{O}_{2}$ is to establish a suitably high electrochemical potential of the catalyst to drive the oxidation reaction, catalysis of ORR and substrate oxidation need not be localized on the same metal particle. Instead, electrically connecting distinct catalysts optimized for each half-reaction should furnish highly efficient aerobic oxidation catalysis in net. Indeed, by providing a quantitative and predictive link between thermochemical and electrochemical catalysis, these studies enable a reimagination of liquid-phase thermochemical catalysis by applying the principles of electrochemistry.

\title{
ASSOCIATED CONTENT
}

\section{Supporting Information.}

Full experimental and analytic details, detailed information of online mass spectrometer, and additional electrochemical and thermochemical analytic data. The Supporting Information is available free of charge on the ACS Publications website.

\section{AUTHOR INFORMATION}

\author{
Corresponding Author \\ *yogi@mit.edu
}

\section{Notes}

The authors declare no competing financial interest.

\section{Acknowledgement}

We thank Thejas Wesley for helpful discussions. This work was supported primarily by the Air Force Office of Scientific Research (AFOSR) under award number FA9550-20-1-0291. The on-line mass spectrometry studies were supported by the Air Force Office of Scientific Research (AFOSR) under award number FA9550-18-1-0420. J.R. acknowledges support from a Samsung Scholarship. Y.S. acknowledges the Sloan Foundation, Research Corporation for Science Advancement (Cottrell Scholar), and the Canadian Institute for Advanced Research (CIFAR Azrieli Global Scholar). C.J.K is supported by the National Science Foundation Graduate Research Fellowship under Grant No. 1122374.

\section{References}

1. Chheda, J. N., Huber, G. W. \& Dumesic, J. A. Liquid-phase catalytic processing of biomass-derived oxygenated hydrocarbons to fuels and chemicals. Angew. Chem. Int. Ed. 46, 7164-7183 (2007).

2. Guo, Z. et al. Recent advances in heterogeneous selective oxidation catalysis for sustainable chemistry. Chem. Soc. Rev. 43, 3480 (2014).

3. Zope, B. N., Hibbitts, D. D., Neurock, M. \& Davis, R. J. Reactivity of the Gold/Water Interface During Selective Oxidation Catalysis. Science 330, 74-78 (2010).

4. Mallat, T. \& Baiker, A. Oxidation of alcohols with molecular oxygen on solid catalysts. Chem. Rev. 104, 3037-3058 (2004).

5. Corma, A. \& Garcia, H. Supported gold nanoparticles as catalysts for organic reactions. Chem. Soc. Rev. 37, 2096 (2008).

6. Carrettin, S., McMorn, P., Johnston, P., Griffin, K. \& Hutchings, G. J. Selective oxidation of glycerol to glyceric acid using a gold catalyst in aqueous sodium hydroxide. Chem. Commun. 7, 696-697 (2002).

7. Davis, S. E., Ide, M. S. \& Davis, R. J. Selective oxidation of alcohols and aldehydes over supported metal nanoparticles. Green Chem. 15, $17-45$ (2013).

8. Tran, H.-V., Doan, H. A., Chandler, B. D. \& Grabow, L. C. Water-assisted oxygen activation during selective oxidation reactions. Curr. Opin. Chem. Eng. 13, 100-108 (2016).

9. Ide, M. S. \& Davis, R. J. The important role of hydroxyl on oxidation catalysis by gold nanoparticles. Acc. Chem. Res. 47, 825-833 (2014).

10. Chang, C.-R., Yang, X.-F., Long, B. \& Li, J. A Water-promoted mechanism of alcohol oxidation on a Au(111) surface: understanding the catalytic behavior of bulk gold. ACS Catal. 3, 1693-1699 (2013).

11. Keresszegi, C., Burgi, T., Mallat, T. \& Baiker, A. On the role of oxygen in the liquid-phase aerobic oxidation of alcohols on palladium. J. Catal. 211, 244-251 (2002).

12. Shang, C. \& Liu, Z. P. Origin and activity of gold nanoparticles as aerobic oxidation catalysts in aqueous solution. J. Am. Chem. Soc. 133, 99389947 (2011).

13. Wieckowski, A. \& Neurock, M. Contrast and Synergy between Electrocatalysis and Heterogeneous Catalysis. Adv. Phys. Chem. 2011, 1-18 (2011).

14. Qi, X., Shinagawa, T., Kishimoto, F. \& Takanabe, K. Determination and perturbation of the electronic potentials of solid catalysts for innovative catalysis. Chem. Sci. 3, (2021). 
52.
Mallat, T. \& Baiker, A. Catalyst potential measurement: A valuable tool for understanding and controlling liquid phase redox reactions. Top Catal. 8, 115-124 (1999).

Mills, A. Heterogeneous redox catalysts for oxygen and chlorine evolution. Chem. Soc. Rev. 18, 285 (1989).

Bindra, P. \& Roldan, J. Mechanisms of electroless metal plating. III. Mixed potential theory and the interdependence of partial reactions. J. Appl. Electrochem. 17, 1254-1266 (1987).

Li, J., Zhong, T.-K. \& Wadsworth, M. E. Application of mixed potential theory in hydrometallurgy. Hydrometallurgy 29, 47-60 (1992).

Chauhan, N. L., Juvekar, V. A., Mahajani, S. M., Suresh, A. K. \& Sarkar, A. Validation of Mixed Potential Theory Using Formic Acid and Ferric Ion as a Redox Couple. ECS Trans. 75, 39-47 (2017).

Miller, D. S., Bard, A. J., McLendon, G. \& Ferguson, J. Catalytic water reduction at colloidal metal 'microelectrodes'. 2. Theory and experiment. J. Am. Chem. Soc. 103, 5336-5341 (1981).

Spiro, M. \& Griffin, P. W. Proof of an electron-transfer mechanism by which metals can catalyse oxidation-reduction reactions. J. Chem. Soc. D Chem. Commun. 1-2 (1969).

Spiro, M. \& Ravnö, A. B. 15. Heterogeneous catalysis in solution. Part II. The effect of platinum on oxidation-reduction reactions. J. Chem. Soc. 78-96 (1965).

Markovic, N. Surface science studies of model fuel cell electrocatalysts. Surf. Sci. Rep. 45, 117-229 (2002).

Mayrhofer, K. J. J. et al. The Impact of Geometric and Surface Electronic Properties of Pt-Catalysts on the Particle Size Effect in Electrocatalysis. J. Phys. Chem. B 109, 14433-14440 (2005).

Lyons, M. E. G., Breen, W. \& Cassidy, J. Ascorbic acid oxidation at polypyrrole-coated electrodes. J. Chem. Soc. Faraday Trans. 87, 115 (1991). Mark E. Davis, R. J. D. Fundamentals of Chemical Reaction Engineering (McGraw-Hill Higher Education, 2003).

Sepa, D. B., Vojnovic, M. V. \& Damjanovic, A. Reaction intermediates as a controlling factor in the kinetics and mechanism of oxygen reduction at platinum electrodes. Electrochim. Acta 26, 781-793 (1981).

Foo, K. Y. \& Hameed, B. H. Insights into the modeling of adsorption isotherm systems. Chem. Eng. J. 156, 2-10 (2010).

Negahdar, L., Zeng, F., Palkovits, S., Broicher, C. \& Palkovits, R. Mechanistic Aspects of the Electrocatalytic Oxygen Evolution Reaction over $\mathrm{Ni}-\mathrm{Co}$ Oxides. ChemElectroChem 6, 5588-5595 (2019).

Petrii, O. A. Pt-Ru electrocatalysts for fuel cells: a representative review. J. Solid State Electrochem. 12, 609-642 (2008).

Tatsumi, H. et al. Alcohol oxidation at platinum-gas and platinum-liquid interfaces: the effect of platinum nanoparticle size, water coadsorption, and alcohol concentration. J. Phys. Chem. C 121, 7365-7371 (2017).

Marinkovic, N. S., Li, M. \& Adzic, R. R. Pt-based catalysts for electrochemical oxidation of ethanol. Top. Curr. Chem. 377, 11 (2019).

Cohen, J. L., Volpe, D. J. \& Abruña, H. D. Electrochemical determination of activation energies for methanol oxidation on polycrystalline platinum in acidic and alkaline electrolytes. Phys. Chem. Chem. Phys. 9, 49-77 (2007).

Rizo, R. et al. Pt-rich core/Sn-rich subsurface/Pt skin nanocubes as highly active and stable electrocatalysts for the ethanol oxidation reaction. $J$. Am. Chem. Soc. 140, 3791-3797 (2018).

Abe, H. et al. Electrocatalytic performance of fuel oxidation by $\mathrm{Pt}_{3}$ Ti nanoparticles. J. Am. Chem. Soc. 130, 5452-5458 (2008).

Zhu, C., Lan, B., Wei, R.-L., Wang, C.-N. \& Yang, Y.-Y. Potential-dependent selectivity of ethanol complete oxidation on Rh electrode in alkaline media: a synergistic study of electrochemical ATR-SEIRAS and IRAS. ACS Catal. 9, 4046-4053 (2019).

Wang, Y., Zou, S. \& Cai, W.-B. Recent advances on electro-oxidation of ethanol on Pt- and Pd-based catalysts: from reaction mechanisms to catalytic materials. Catalysts 5, 1507-1534 (2015).

Gu, Q., Sautet, P. \& Michel, C. Unraveling the role of base and catalyst polarization in alcohol oxidation on Au and Pt in water. ACS Catal. 8 , $11716-11721$ (2018).

Ledezma-Yanez, I. et al. Interfacial water reorganization as a pH-dependent descriptor of the hydrogen evolution rate on platinum electrodes. Nat. Energy 2, 17031 (2017).

Chen, X., McCrum, I. T., Schwarz, K. A., Janik, M. J. \& Koper, M. T. M. Co-adsorption of cations as the cause of the apparent pH dependence of hydrogen adsorption on a stepped platinum single-crystal electrode. Angew. Chem. Int. Ed. 56, 15025-15029 (2017).

Spendelow, J. S. \& Wieckowski, A. Electrocatalysis of oxygen reduction and small alcohol oxidation in alkaline media. Phys. Chem. Chem. Phys. 9, 2654 (2007).

Rodriguez, P. \& Koper, M. T. M. Electrocatalysis on gold. Phys. Chem. Chem. Phys. 16, 13583-13594 (2014).

Quaino, P., Luque, N. B., Nazmutdinov, R., Santos, E. \& Schmickler, W. Why is gold such a good catalyst for oxygen reduction in alkaline media? Angew. Chem. Int. Ed. 51, 12997-13000 (2012).

Kwon, Y., Lai, S. C. S., Rodriguez, P. \& Koper, M. T. M. Electrocatalytic oxidation of alcohols on gold in alkaline media: base or gold catalysis? J. Am. Chem. Soc. 133, 6914-6917 (2011).

McCrum, I. T. \& Koper, M. T. M. The role of adsorbed hydroxide in hydrogen evolution reaction kinetics on modified platinum. Nat. Energy 5 , 891-899 (2020).

6irdja, Y. Y. et al. Advances and challenges in understanding the electrocatalytic conversion of carbon dioxide to fuels. Nat. Energy 4, 732-745 (2019).

Chen, X., McCrum, I. T., Schwarz, K. A., Janik, M. J. \& Koper, M. T. M. Co-adsorption of cations as the cause of the apparent pH dependence of hydrogen adsorption on a stepped platinum single-crystal electrode. Angew. Chem. Int. Ed. 56, 15025-15029 (2017).

Cheng, T., Wang, L., Merinov, B. V. \& Goddard, W. A. Explanation of dramatic pH-depe
greatly weakened water adsorption at high pH. J. Am. Chem. Soc. 140, 7787-7790 (2018). Sarabia, F. J., Sebastián-Pascual, P., Koper, M. T. M., Climent, V. \& Feliu, J. M. Effect of the interfacial water structure on the hydrogen evolution reaction on $\mathrm{Pt}(111)$ modified with different nickel hydroxide coverages in alkaline media. ACS Appl. Mater. Interfaces 11, 613-623 (2019).

Ryu, J. \& Surendranath, Y. Tracking electrical fields at the $\mathrm{Pt} / \mathrm{H}_{2} \mathrm{O}$ interface during hydrogen catalysis. J. Am. Chem. Soc. 141, 15524-15531 (2019).

Sheng, W. et al. Correlating hydrogen oxidation and evolution activity on platinum at different $\mathrm{pH}$ with measured hydrogen binding energy. Nat. Commun. 6, 5848 (2015). 